\title{
Critical realism and economic anthropology
}

\section{Dr John Harvey}

Nottingham Business School, Nottingham Trent University, Nottingham, United Kingdom

Email: john.harvey@ntu.ac.uk

Telephone: $+44(0) 1158488129$

John Harvey is a senior lecturer at Nottingham Trent University. His research interests include altruism, gift giving, and interdisciplinary issues in economic anthropology

\section{Professor Andrew Smith}

Nottingham University Business School, University of Nottingham, Nottingham, United Kingdom

Email: andrew.p.smith@ @ottingham.ac.uk

Andrew Smith is currently the Professor of Consumer Behaviour at Nottingham University Business School. He has had work published on various aspects of consumer decision making and behaviour including ethics, behavioural data analysis and data management.

\section{Dr David Golightly}

Human Factors Research Group, University of Nottingham, Nottingham, United Kingdom

Email: david.golightly@nottingham.ac.uk

David Golightly is a senior research fellow at the Human Factors Research Group, University of Nottingham. He specialises in the field of cognitive ergonomics, understanding the factors that make technology and systems fit for the intended user's needs and cognitive abilities. 


\section{Critical realism and economic anthropology}

This paper discusses basic critical realism within the context of economic anthropology and develops an approach to studying material relations between people. A diachronic form of analysis, following the work of Bhaskar and Archer, is described as a practical means of analysing property rights. This new approach emphasises epistemic relativism and ontological realism in order to compare disparate forms of human interaction across cultures. The aim of doing this is to develop a philosophical framework that allows for the comparison of economic practices without resorting to judgemental relativism. The implications are significant for institutional economics and anthropology alike, particularly for researchers examining multiple overlapping practices such as market and gift exchange.

Keywords: economic anthropology, social structure, property rights

\section{Giving out or giving in? Epistemological ambiguity and economic interaction}

Giving, sharing, buying, selling, exchanging, swapping, taking, stealing, borrowing, lending, loaning, investing, inheriting, donating, receiving, sacrificing ...

The words shown above are used in everyday language, by laypersons and academics alike, to describe ways in which humans interact. The history of anthropology reminds us that these concepts are often culturally specific rather than universal. For instance, if we speak of 'giving', we may be referring to giving presents, giving alms, giving time, giving up, giving in, giving out, giving things, giving ideas, giving permission, giving dowry, giving blood, or even giving people, depending on when and to whom we speak. Defining universal forms of human interaction is therefore challenging because meaning often appears to be situational or dependent on local variables. Indeed, issues of classification are the primary reason that some anthropologists have discouraged comparison between 
cultures, and - in doing so - have fundamentally challenged the basis of the discipline (see for instance, the recent debate in HAU Journal - 'Incomplete regularities', da Col, 2015). If social practices can only be understood by means of localised historical accounts, after all, why bother comparing cultures? This question, and our rebuke, form the basis of this article. It advances an argument which entails that comparisons of human interaction are not only possible, they are imperative if anthropology is to provide a full and proper account of the way economies form. The basis of the comparative method presented for consideration draws explicitly on the critical realist notions of ontological realism and epistemic relativism. To paraphrase Bhaskar $(2002,39)$, knowledge is part of reality. Indeed, epistemology, properly understood, is a part of ontology, as competing beliefs exist in the same world as the objects about which they (aim to) speak.

To fully articulate an approach based on these positions, the first section of this article will begin by considering some recurring ontological themes in economic anthropology, all of which have pulled this field of study in opposite directions. The article then moves on, in the second section, to consider the question 'what must the world be like for humans to be able to form economies?', and it suggests that reality is to some extent precategorised by the economic goods around us. Indeed, in line with Bhaskar's approach this section will argue that reality is 'always already pre-categorised $[\ldots]$ prior to and independently of any human categorisation of it' (Hartwig 2007, xvii). In short, categories are not something humans impose on reality, they are literally the stuff of reality itself. Bhaskar argued that the intelligibility of categories, and thus the possibility of scientific knowledge, depends on the interrelation between two separate domains: the transitive and the intransitive. The transitive domain constitutes the ways in which humans collectively interpret, describe and theorise existence. In the context of this article this domain therefore contains shared forms of property rights. The intransitive domain, by contrast, 
consists of those aspects of the world which exist independently of scientific practice, but are nonetheless the intended targets of our knowledge claims.

We subsequently argue, in the third section of the article, that the wide variety of observable political economies has led many anthropologists towards synchronic forms of analysis, particularly practice-based approaches, which fail to provide explanatory accounts of social change. We suggest that the critical realist canon can help to provide a potential resolution to the recurring debates that were discussed in the previous section. This initial proposition will then be used as a springboard for developing a philosophical framework which allows for the diachronic analysis of property rights. This approach attempts to avoid relativist descriptions of human interaction by focusing explicitly on the importance of ontological realism.

\section{Give and you shall receive - Recurring themes in economic anthropology}

For the past century, economic anthropology has been concerned with the ways in which people from different parts of the world produce, consume, and exchange both themselves and the things around them. Comprehensive histories of the discipline, which document its engagement with these key themes, have been written in recent years (e.g. Hart and Hann 2011; Chibnik 2015; Carrier 2005; Wilk and Cliggett 2007). Our aim in this article is therefore not to repeat such work. Nonetheless, it is worth starting out by briefly reiterating some prominent discussions before examining what contribution critical realism might be able to make to them.

In seminal work by economic anthropologists such as by Boas, Mauss or Malinowski, there is a common fixation on the ways in which things are exchanged and circulate 
between people. Typical questions ask: in which direction do objects of value circulate? Why do people exchange seemingly trivial things without practical function? Can moral equivalence ever be achieved through economic exchange? And, does reciprocity underpin all human relations? The extent to which observed actions can be described in utilitarian terms as either selfish or selfless, interested or disinterested formed much of the debate that followed. Importantly, this debate was not restricted to just the Englishspeaking world. The Revue du Mauss in France, for instance, was created explicitly as an attempt to counter inappropriate utilitarian interpretations of Maussian thought (Caille, 2014).

These tensions persist today, and have led to several notable disagreements. For instance, a major tension in 20th century economic anthropology emerged from a conflict between anthropologists who adopted 'formalist' and 'substantivist' perspectives. This distinction is no longer a major focus for discussion, although arguably it should be, because many of the issues that were identified by both sides have not yet been resolved. As Hart and Hann (2011) note, the formalism/substantivism debate was essentially a rehashing of the methodenstreit (or 'Battle of Methods') that occurred in Germany during the late 19th Century. The historical accounts mentioned previously provide an extensive discussion of the debate, but - for the purposes of this article - it is worth beginning this section by quoting a passage from Chibnik (2015) in full, which eloquently summarises a number of the key issues:

'The formalists (e.g. Burling 1962; LeClair 1962; Cook 1966) thought that economics is about methods used to analyze decision making in situations where resources were scarce. They argued that methods such as cost-benefit analyses could be used in all sociocultural settings. The substantivists (e.g. Dalton 1961) said that economics is about 
institutions associated with production, consumption, and (especially) exchange. They argued that in places where markets were non-existent, most choices are not the result of individuals carrying out informal cost-benefit analyses. Instead, these choices are “embedded" in institutional settings with particular cultural norms.'

Substantivists therefore reject the idea that economic transactions can be understood in isolation, insisting instead that they must be understood as 'a momentary episode in a continuous social relation' (Sahlins 1968, p.139). The ontology of substantivism emphasises the importance of culture and social structure, rather than simply the behaviour of individuals. When using the word 'economy' substantivists are therefore really referring to a sub-category of cultural interaction, rather than the rationalising behaviour of people in the face of scarce resources, as is typical of the economics discipline. This emphasis on the embedded nature of economic transactions led them to describe basic archetypes of social interaction. For Levi-Strauss (1949/1969) and Sahlins (1979) these archetypes centred around reciprocal forms of interaction, whereas for Polanyi (1944, 1957) economic provisioning occurred through three distinct forms: market exchange, reciprocity, and redistribution. A methodological criticism that is commonly levelled at attempts to explain economic behaviour in these archetypical ways is that it leaves no scope for the agency of individuals. If all economic behaviour is classified as reciprocal, after all, there is no potential to explain transformations of social structure through agency. The ontology of substantivism therefore lacks 'depth', and, in Archer's terms, results in the fallacy of downward conflation, which is the 'presumption that the forces of socialisation simply imprint themselves as beliefs upon agency' (2003, $51)$.

Formalists, by contrast, argue in favour of a utilitarian perspective that privileges 
methodological individualism, and their work thus presupposes no such 'basic' forms of social interaction. This approach experienced its heyday in the 'neoclassical' work of Becker (1976), and the ontology which it employs, like the substantivist ontology, is flat. The agency of the individual is the object of study, while any social/cultural properties and powers are understood as the epiphenomenal effects of other people. In Archer's terms this type of approach therefore involves a form of upward conflation. Proponents on either side of the debate make distinct ontological commitments, while rejecting others. As Sahlins $(1969,15)$ has rightly noted 'at issue ... is the ontological locus of economy. The disagreement is thereby decisive: all other differences of method and conception follow logically from it.'

Even at the height of this debate it was therefore noted that both sides were effectively 'talking past one another' and 'operating within separate spheres of discourse' (Cook 1966, 323). We believe that this situation has continued for the past 50 years, even if the debate has taken on new names. In general, anthropology and economics seem to have fallen out, as each discipline ekes out a justification for its own separate existence. Although it is encouraging to see recent anthropological debates over ontology such as the one between Viveiros de Castro (2015) and Graeber (2015) - the latter of whom writes from a critical realist perspective - ontology is rarely an area of explicit discussion between economists and anthropologists.

One key reason for this is the fact that researchers are increasingly choosing to privilege 'practice' theories (particularly inspired by the work of Wittgenstein or Bourdieu 1977, 1984) and local descriptions. Practices are described as being in opposition to approaches that impose fixed concepts on the subject of study. One positive consequence of taking practices as the unit of sociological analysis in this way has been the fact that it highlights 
how traditional base/superstructure, market/mutuality or gift/commodity dualisms result in misleading conclusions, because they wrongly suppose a universal economic morality. Research utilising practice theory has therefore also critiqued the notion of property rights, and has even critiqued individual personhood itself. Both concepts can be considered problematic from this perspective if they are applied to people who simply do not imagine themselves in strict binary terms such as those that are inherent to Cartesian subject/object dualism. Strathern (1988) and Wagner (1991), for instance, describe 'how Melanesians typically interact as composite beings constituted of the detached parts/relationships of other persons through prior agentive elicitations and exchanges' (quoted in Mosko 2010, 215). More broadly, ethnographic insights into the range of ways in which people conceptualise themselves and the world around them have led some anthropologists, such as Gudeman $(2008,32)$, to view the task of the interlocutor as one that reproduces people's own economic constructions, taking into account their conjoint or disjoint sense of self.

There are numerous critical realist commentaries on issues relating to practice-based studies (Archer 2000; Bonnington 2015; Ashraf and Uddin 2015) and it is not our aim to rehearse the critiques that these commentaries have produced here. It is worth noting, however, that, for Wittgenstein, it was sufficient for philosophers to 'treat only the network and not what the network describes' (Wittgenstein 1961, 6:35). This is insufficient if we are to account for the ontological basis of economics, or, in other words, to account for the ways in which people interact with different categories of goods. Critical realists, in contrast to formalists, substantivists, and practice theorists, speak of 'depth' or 'stratified' ontologies as central to social interaction, and, in this way, they provide an alternative meta-theoretical basis that - we will argue - can account for structure, agency, and culture without reducing one to (the) other(s). In the following 
section we discuss how anthropologists have thought about the ways ontology influences economics, before developing a critical realist-informed method that would allow them to study the transformation of economies.

\section{Economic goods and the pre-categorisation of social reality}

According to Bhaskar (2002/2012), people misunderstand the nature of categories; they think, like Kant, that categories are things that we impose on reality. To the contrary, Bhaskar suggested that categories are real, and that they are constitutive of reality itself. Therefore, for Bhaskar, causality is not a schema that we impose on reality; it is actually out there. Furthermore, the subject matter of philosophy, traditionally defined as the understanding of categories, must now be defined as reality itself, as being. As Bhaskar explains:

This becomes very important when we move to the social world because we can then argue: reality is pre-categorised, but in the social world the way in which reality is categorised may be false. Social reality is conceptually dependent; the categories in terms of which we understand social reality may be systematically illusory, or misleading, and that is the clue to the concept of ideology. (Bhaskar 2002/2012,54)

So how is social reality pre-categorised? In Bhaskar's account, pre-categorisation is a result of structure and essence. Indeed, as Rutzou $(2017,10)$ notes, the role of the scientist is said 'to move beyond collecting conjunctions of events towards 'the things themselves'; the essence behind the appearance which accounts for the appearance', and these 'things can be grouped together based on their common constitution 'despite their manifest sensible differences' (Bhaskar, 1975/2008, 201). In other words, essences and structures in Bhaskar represent the more fundamental nature of things, and the more fundamental 
things of nature.' Essentialist accounts of social interaction have often been resisted in anthropology, but there are nonetheless a limited number of examples that have had an influence. The structuralism of Levi-Strauss provides an obvious example from the mid20th century. Like Marx and Freud before him, Levi-Strauss (1955/2011, 57) described the social scientist's role as one that uncovers knowledge, and he maintained that - despite the many observable variants of human interaction - social phenomena possess stable underlying structural characteristics. In the past two decades there have been other attempts by anthropologists to describe the way social reality is pre-categorised. These approaches have sought, in particular, to address the issue of reciprocity, which LeviStrauss placed centre-stage throughout his work. Two researchers whose work on these issues has been influential are Fiske $(1991,1992)$ and Descola $(2013 ; 2014)$.

Fiske has developed a typology of social interaction based on extensive ethnographic evidence. The four 'elementary' forms of social interaction that, he suggests, occur among all people are: 'Communal Sharing', 'Authority Ranking', 'Equality Matching', and 'Market Pricing'. These four forms, Fiske argues, are generative epistemological schemata, in the sense that children of all cultures are born prepared to recognise these forms in later life, and, in being able to do so, can participate in collective action and moral judgement. Although the prevalence of these forms will vary in different groups of people they are said to be 'fundamental, in the sense that they are the lowest or most basic-level "grammars” for social relations' $(1991,25)$

Descola rejects the essentialist reciprocity of Levi-Strauss as an inappropriate leitmotif that recurs throughout Western thought, and begins from a different starting point than Fiske. Though he concedes that humans share a basic set of cognitive and sensory-motor 
dispositions, he argues that the task of the anthropologist is to investigate why some cultures privilege salient features of social and environmental relations, whereas others ignore them. His central thesis is that all human interaction (and cultural variation) results from a limited but varied set of ontological predicates, or ways of apprehending the world/being. These predicates influence the way people subsequently pick out salient features of culture and nature (a dualism he suggests results from a Western account of knowledge). The extent to which these features are socially significant accounts for the ways in which people understand and relate to other organisms, whether human or nonhuman, and forms the basis of how people classify the world around them. The four ontological predicates distinguished by means of Descola's phenomenological insights are supported by a range of ethnographic evidence and are termed: 'animism', 'totemism', 'analogism', and 'naturalism'. These four common tropes have recurred throughout the history of anthropology. There is clear merit in using these proposed distinctions as a basis for general comparison, because it helps us to move beyond the ethnocentrism that is present in so much of anthropology. However, Descola's use of the word 'ontology' potentially introduces some confusion about the proposed object of anthropology and the role of the researcher. As Searle (2010) notes, there are at least two different senses of the objective/subjective distinction: one that relates to knowledge (epistemology) and one that relates to existence itself (ontology). A pain or an itch is ontologically subjective because it only exists insofar as it is experienced by a human subject. In contrast, a mountain or a tree can be said to be ontologically objective, as their mode of being does not depend upon a knowing subject. Itches and mountains are both real, but they are manifestations of different modes of existence. The epistemic sense in which an objective/subjective distinction can be applied therefore relates to what is being claimed in a proposition. For instance, the statement 'Roy Bhaskar died in England' is 
epistemically objective. Its truth or falsity can be interrogated regardless of the attitudes of observers. However, the statement 'Roy Bhaskar is the greatest philosopher to have ever lived' is epistemically subjective, it depends upon the knowledge and opinions of the observer. One of the main challenges for anthropologists hence occurs during classification, when trying to distinguish between claims (the epistemic status of statements) and entities (modes of existence).

Both Descola and Fiske have, in their own respective ways, described the way social reality results from pre-categorised forms of interaction that occur because of the presence, or indeed absence, of particular epistemological schemata. These initial building blocks of human thought, which form the basis of social relationships, are described in prototypical terms. They are universal features of human thought but, when they are observed ethnographically or when the descriptions that people give of themselves are interpreted, the inevitable consequence is analytical hybridity. That is to say, the forms of human practices that are observed are seldom of the prototypical form initially imagined, so they appear as polythetic or fuzzy categories ${ }^{\mathrm{i}}$. We believe there is merit in such approaches, but also feel that they result in an overlap between epistemology and ontology that requires clarification. We are interested in providing such clarification by asking the question: "what must the world be like for humans to be able to form economies?' We believe that, in order to provide an answer to this question, the ontological basis of human interaction must first be considered. As critical realist thought has its origins in similar questions, we believe it may offer further insight to anthropologists. 
Bhaskar (1975/1977, 1998) and Archer (1982, 1995, 2007, 2012) offer the clearest methods in the critical realist canon for identifying the ontological presuppositions of social interaction. Bhaskar's Transformational Model of Social Activity (TMSA) and Archer's Morphogenetic Sequence both describe ontological commitments that are maintained regardless of context. As others have noted (Porpora 2015; Gorski 2013), however, ontological presuppositions cannot explain anything in isolation, they must be built upon. It is common for critical realists to speak of the ontological basis of social structure, sometimes described as the 'material relations' that exist between people. However, less attention has typically been paid to the material world itself, to which social relations are assumed to relate. A recent example of this is apparent in the work of Donati and Archer $(2015,199)$, in which goods are described as 'intangibles' that are the consequence of collective intentionality. This description is unlike other influential contemporary theories and theorists that have attempted to describe the metaphysical basis of socio-materiality, including such approaches as Actor-Network Theory (Latour 2005), Assemblage Theory (Delanda 2006, 2016), Object-Oriented Ontology (Harman 2010, 2016; Bryant 2011), and Material Engagement Theory (Malafouris 2013). These forms of inquiry all give more explicit consideration to things, regardless of whether they are human or not. In this respect, critical realist economists and anthropologists have perhaps not emphasised the 'ontology of things' that Bhaskar outlined in A Realist Theory of Science $(1977,223)$ to a sufficient degree. For Archer $(2000,168)$ the affordances of objects and their dispositional capacity to be understood is central to her account of culture. Likewise, for Bhaskar, the enduring structure of particular kinds - whether they are emeralds, figs, desk lamps, or cabinet ministers - is what makes science possible. We contend that the methods of economic anthropology can be bolstered by re-examining Bhaskar's claim that 'things persist' (ibid). Indeed, more specifically, this can be 
achieved by considering how different types of goods serve as antecedent generative mechanisms for human interaction.

In institutional economics, things in the material world are generally referred to as 'goods', particularly following the work of Ostrom (who expanded on the work of Samuelson 1954; and Musgrave 1959). In Ostrom's account goods pre-categorise what we might do with them. A simple matrix can be constructed by asking whether a good is a) excludable (i.e. can a person prevent another from interacting with it?), and b) subtractable (i.e. if one person interacts with a good, does this prevent someone else from interacting with it?). Asking these two basic questions gives the following four categories of goods (Hess and Ostrom 2003,120) :

1) Public Goods: Low subtractability and difficult to exclude

2) Common-Pool Goods: High subtractability and difficult to exclude

3) Club Goods: Low subtractability and easy to exclude

4) Private Goods: High subtractability and easy to exclude

These four categories of goods provide a basic insight into how people interact with goods, and should arguably be commended by critical realists because they clearly delineate different types of goods from the property rights that people assign to those goods. This is important because it allows for the possibility that qualitatively different property rights may simultaneously overlap between people for one type of good. Goods are ontologically real and are associated with competing relative claims of ownership. The great strength of Bhaskar's TMSA and Archer's Morphogenetic Sequence, however, is that they describe change in the social structure through time. This feature is not 
explicitly mentioned in the model that is shown above, and we therefore suggest that an extra feature worth considering is simultaneity during interaction. If we aim to understand human interaction in synchronic terms the table above provides an initial starting point, but we would argue that it is more important that changes in structure are able to be analysed diachronically. The T-variable is of key importance because it contributes to what we can do with goods. For example, you can read this paper and then give it to your friend to read, but it is harder to read it simultaneously without some potentially awkward manoeuvring! Ostrom's work shows how property rights can exist simultaneously, and how they can overlap for multiple individual people and/or institutions. In all she identifies seven types of property rights, summarised below (Ostrom and Hess 2007,16):

1) Access: the right to enter a defined physical area and enjoy non-subtractive benefits.

2) Contribution: the right to contribute to the content.

3) Extraction: the right to obtain resource units or products of a resource system.

4) Removal: the right to remove one's artefacts from the resource.

5) Management / Participation: the right to regulate internal use patterns and transform the resource by making improvements.

6) Exclusion: the right to determine who will have access, contribution, extraction, and removal rights, and how those rights may be transferred.

7) Alienation: the right to sell or lease management and exclusion rights.

For any one good, multiple simultaneous property relations can apply to qualitatively different aspects. To give a practical example of overlapping property rights, we might consider the annual critical realism conference. Each year the conference alternates between different international host universities. Typically, the room in which conference 
attendees discuss their work is owned by the university itself. This ownership is, in most cases, formalised and legally underwritten by the state, such that the university has a complete right of 'alienation' over the property. Senior management of the university will often delegate rights and responsibilities to individual schools or divisions. The dean or manager of the host school will usually possess the right to determine who can use the room for practical purposes; they thus have a right of exclusion. Researchers within a school are normally responsible for organising the conference, and they are therefore given management rights to organise a timetable for the room and arrange which speakers will speak and when. Delegates of the conference are permitted the right to extract/contribute to the room, by listening or participating in discussions. Finally, other members of the university staff are associated with the conference proceedings indirectly, from cleaners to administrative staff and catering personnel, who will likely access the room to contribute or maintain the subtractive benefits for the delegates. These distinctions help to illustrate how institutions and individuals interact synchronically through overlapping property rights. To understand how these deontic relations change, however, it is also necessary to consider the role of human agency.

\section{How can critical realism aid diachronic analysis of property rights?}

Critical realism has helped to inform studies in economics, economic sociology, and economic anthropology alike (e.g. Lawson 2003; Elder-Vass 2015; Graeber 2001, 2015). We contend, however, that critical realist ontology can help support retroductive forms of explanation for all forms of economic interaction. In order to understand why we believe this to be the case it is necessary to, first, acknowledge the fact that the selfconceptualisation that people make use of when they interact is of course not universal. Indeed, culturally-specific varieties of epistemology are sometimes described by 
anthropologists as incommensurable cosmogonies of thought. This is a tension that Bhaskar explicitly discussed with others, including the discourse analyst Ernesto Laclau. In an illuminating discussion between the two, the latter suggested the following:

"Just as you speak your native language before you learn its grammar and the task of the grammarian is to bring out the immanent grammatical structure which constitutes that language, so the task of the discourse analyst is to explore the immanent grammars which underlie all kinds of meaningful intervention."

Laclau in Bhaskar 2002, 80

What would an immanent grammar of economics look like? What is the social ontology implicit to all forms of economic interaction, regardless of the way different people think about the world? The critical realist position, similar to the position that is adopted by Laclau above, would no doubt emphasise structure, but would also include agency and culture. We contend that an explication of such a grammar, if possible, requires of us that we recognise that the process through which people acquire knowledge varies depending on culture and context, but we also maintain that this fact does not result in an account of knowledge which is rooted in judgmental relativism. Knowledge of property and property regimes is conceptually mediated in the same way as scientific knowledge. The economic objects (goods) that we define, denote, and discuss are fallible and subject to revision, but they nonetheless undergird our understanding of the world and our relative place within it.

Some authors (e.g. Verdery and Humphrey 2004; Busse 2013) have rightly questioned the limits of a number of the analytical categories that are discussed within this article 
such as personhood and property. These categories reinforce a Cartesian worldview and give rise to a particular historical epistemology. Consequently, there is a question as to whether property regimes are 'out there' waiting to be discovered in the world, or whether they are a Western fiction. These questions about the epistemic status of categories are valuable and worth considering. We contend, however, that regardless of whether people construe themselves as subjects/objects, or whether they have formalised property rights, they do share forms of collective intentionality. Intentionality in the philosophical sense refers to the 'aboutness' of consciousness. It is the capacity of the mind by which it is directed at, or about, objects or states of affairs. Whether you want to read this article, believe that it is raining outside, fear the dentist, or have a preference for apples over oranges, you are in each case in an intentional state of mind. Each of these cases is expressed in first-person singular. However, more generally, intentionality:

'seems to depend upon the feature that persons are material things with a degree of neurophysiological complexity which enables them not just, like the other higher-order animals, to initiate changes in a purposeful way, to monitor and control their performances, but to monitor the monitoring of these performances and to be capable of a commentary upon them ' (Bhaskar 1998,38).

This second-order capacity for monitoring enables people to retrospectively comment on their actions, and thus allows them to communicate about their intentional objects with other people. Identifying and articulating such intentional objects provides the possibility for forms of collective intentionality e.g. 'we believe in $X$ deity' or 'we are creating a binding contract of repayment'. Collective intentionality is thus, by virtue of its existence, accompanied by relations between people, which we refer to as deontic boundaries. The 
property rights shown in Table 2 are a Western example of deontic boundaries and an attempt to classify material relations in general terms. However, these relations are not universal schemata because they are localised and predicated upon competing metaphysical claims. Property rights are neither universal nor static. Instead they are both contextual and subject to on-going revision. Collective intentionality is a prerequisite of human interaction, and it is on these shared intentional objects that economic anthropology must focus. The starting point for any comparative anthropological metatheory is whether it is generalisable, so we might begin by examining the ethnographic accounts that appear to explicitly contradict the presuppositions described above. For judgmental relativists, radical counterexamples to (supposedly universal) human practices are the exceptions that are used to justify their rejection of comparative method.

A possible entry point to thinking about radical perspectives on property rights is communities that have demonstrated historical resistance to private alienation of property. There are dozens of case studies (e.g. Gibson 1985; Endicott 1988) that could be selected here, but an interesting example of a culture that is both mindful of, and yet radically opposed to, private property legislation are the Hutterites of North America. These small communes of typically around 150 people believe in the concept of 'Gelassenheit' (yielding to God) and 'Gutgemeinschaft' (living in a community of goods where everything is shared). The idea of individualised private property is rejected outright in such a way that 'brethren' (members of colonies) must forsake all concern for personal property in favour of a complete community of goods (Hofer 1982). Despite this all-encompassing form of theocratic communism, the brethren do nonetheless have highly-particularised forms of interaction with goods that flow through the economy. Divisions of labour are further a central feature of the communes, particularly for 
religious and educational roles, despite some interdependence between responsibilities. Various historical studies (e.g. Peter and Whitaker 1981; Longhofer 1993; Janzen and Stanton 2010) have also described how these communal arrangements are contingent upon conflict avoidance, inter-communal forms of trading, and even individualised access rights to controversial goods such as mobile phones. The Hutterites therefore serve as an example of people with fundamentally different ideas about the moral status of property, but a diachronic analysis of property rights can help serve to understand how alternative forms of economy are structured. In economies that are opposed to money and exchange anthropologists must resort to studying how property rights transform across subsets of the population in question.

As a contrast, we might examine groups of people that describe their own subjectivity and personhood in terms that are radically different from those that are entailed by a Cartesian subject/object worldview. To the best of our knowledge all human languages do at least provide an apparatus for people to conceptualise their 'selves' in relation to entities and events, regardless of whether the constituent persons, objects, and 'worlds' designated are understood in such terms. For example, in the Amondawa (Tupi Kawahib) language there is no linguistic space-time mapping, but there is nonetheless an implicit account of entities and inter-event relationships (see Sinha et al, 2011). This means that, though their language may provide obscure emic categories, the Amondawa do nonetheless participate in collective intentionality. Similarly, an extreme example is apparent in controversial debates over the grammar and cognition of the Pirahã people, a small group of indigenous hunter-gatherers in the Amazon rainforest (see Everett 2005; Nevins et al. 2009; Everett 2009). The Pirahã are monolingual and their language lacks words to explicitly describe cardinal or ordinal numbers, colours, or absolute directions, 
and Everett (2005) has drawn attention to both the lack of relative clauses and the absence of grammatical recursion. The group has a highly egalitarian kinship structure which lacks social hierarchy and avoids coercion. Interestingly, they have no obvious creation myth and, instead, describe a perennial state of being - the world has always been as it currently is. Consequently, the Pirahã description of the world is akin to a kind of empirical realism. Even in such a restrictive language, however, it is possible to describe the things that circulate between people, and it is these collective intentional objects that should inform the description of economic life. As Appadurai $(1988,5)$ has suggested:

"...we have to follow the things themselves, for their meanings are inscribed in their forms, their uses, their trajectories. It is only through the analysis of these trajectories that we can interpret the human transactions and calculations that enliven things. Thus, even though from a theoretical point of view human actors encode things with significance, from a methodological point of view it is the things-in-motion that illuminate their human and social context.

Despite the huge variation illustrated by ethnographic evidence about the ways in which people apprehend the world, collective forms of intentionality are a prerequisite for all human interaction. We contend that a diachronic analysis of agency and structure can be used to understand the apprehension and appropriation of goods, regardless of the culturally specific property rights that define appropriation. If this proposition is accepted, it becomes possible to formalise the relationship between people in any given economy.

\section{What might diachronic analysis mean for anthropological method?}

"Actors do not behave or decide as atoms outside a social context, nor do they adhere slavishly to a script written for them by the particular intersection of social categories 
that they happen to occupy. Their attempts at purposive action are instead embedded in concrete, ongoing systems of social relations."

(Granovetter 1985,487)

Economic sociologists such as Granovetter, much like the earlier substantivists, draw attention to the idea that economic interaction cannot be analysed as being somehow separate from socio-cultural contexts. People are embedded in networks of social relations and the economic decisions they make as individuals are thus necessarily influenced by those same social relations. Various historical authors have used the language of 'networks' to describe economic relations. Radcliffe-Brown $(1965,197)$, for instance, has suggested that the 'economic machinery of a society' could only be understood through a networked description of social structure. Evans-Pritchard (1940, 17) has furthermore described the network of property rights over cattle as a fundamental feature of Nuer kinship, while Simmel $(1950,135)$ has argued that sociological analysis should emphasise triads ('associations of three') instead of dyads. Anthropologists have also, on occasion, attempted to use network theory as a basis for practical ethnographic research (e.g. Hage and Harary 1996). A wide range of social scientists have further sought to use digraphs in order to model trust, friendships, alliances, and communication networks to better understand human relations. However, approaches that use digraphs to model property relations are much less frequent in the literature than approaches that examine kinship or social goods.

The relative lack of work examining economic property rights as networks is perhaps a legacy of work that promotes polythetic means of classification. Various anthropologists (e.g. Needham 1975; Laughlin 1993) have drawn attention to the problem of categorising 
human activity through monothetic forms of classification. As noted earlier, analytical hybridity can lead to an argument for polythetic classification and the use of practice theory as a more appropriate means of describing human interaction. The typical argument for polythetic classification is that it helps to eliminate category errors and avoids a misplaced sense of concreteness. This stance has been particularly influential for anthropologists revisiting and rejecting the legitimacy of kinship categories identified by earlier work (e.g. Godlier 2004/2011). For Needham (1971, cvii) the general definitions used when defining kinship (such as incest or marriage) were - in attempting to be 'allpurpose words' - actually abusive generalisations. He went on to argue that:

it is not that we cannot make sociological inferences, about institutions, groups, and persons, from the structure of a terminology, but we cannot even infer that the statuses denoted by any one term will have anything significant in common ... Kinship is certainly a thoroughly misleading term and a false criterion in the comparison of social facts. It does not denote a discriminate class of phenomena or a distinct type of theory.'

This has significant implications for the comparative method, because it illustrates the necessity of epistemic relativism. For instance, in economic anthropology it means that when an observer sees a one-way transfer of material wealth they should restrict themselves from categorising the transfer in terms such as 'gift' or 'bribe', as if these were universal forms of behaviour (an illustrative example can be seen in the practice of 'Guanxi' in China - see Smart 1993). By keeping this issue in mind, however, it encourages the researcher to try and understand people on their own terms, to presume no universal morality, and to categorise action in relation to a broader set of social facts. Practices consequently preclude comparison, and this raises a profound issue for 
normative economic science. We suggest that there must be an attempt to move beyond polythetic categorisation, and that this may only be possible by recognising the ontological basis of human interaction. Here we use the word ontology not as a 'predicate', as Descola describes it, but in the critical realist sense, as the way the world must be for science to be possible.

We have so far tried to establish that there is a distinction between goods and the property rights that people assign to them, and that neither aspect can be sacrificed for the sake of method. Instead, there is a modal ontological distinction between the two, which means that people have and share a knowledge of goods that corresponds to reality, albeit fallibly. Property rights are a transitive feature of social structure: they can pass between individuals, or people in unison, through discrete transfers (e.g. giving or exchanging). To give, to steal, or to share are all examples of transitive verbs which require an intermediary object for them to be intelligible. For example, giving, stealing, and/or sharing only make sense if there is an object which a person can make use of, such as money, time, land or food. We contend that transitivity is the basis on which all humans transform and/or reproduce cultural rules of appropriation and expropriation (note that here we are using the word transitivity to refer to the subject-predicate relation specifically, although as a knowledge claim it also clearly falls within what critical realists refer to as the 'transitive domain'). These rules provide the basis for humans to create replicable, stable forms of interaction that allow both for property itself and for the relative rights that are assigned to property. In addition to this, property rights can be bestowed upon others without explicit interpersonal recognition (e.g. by decrees that give a whole population access to a resource), in which case the property rights of the whole social structure undergo a qualitative transformation. This leads to the conclusion that 
structure, agency and culture are all fundamentally important when studying economies, and proper analysis must therefore involve a diachronic examination of multiple overlapping property rights. Changes in property rights over time reveal how people are enabled or constrained to participate in the economy. If people and the property rights between them are formally represented it is common for multiple relationships to exist simultaneously. We refer to overlapping social relationships as multiplexity. All human life is bound up in relationships that overlap with goods and other people. The challenge for the anthropologist is to understand how these relationships exist, often in the absence of empirical data (e.g. for imagined relationships with deities).

One other notable feature of human interaction is that, in many cases, we act on behalf of other people. In legal terminology, this sometimes gets called the agent-principal relationship. This 'institutional' form of agency is important for anthropologists who are involved in the process of examining the economy because the transactions in question often relate to political trade, tax, or redistribution. In the case of some anthropological fieldwork this is a challenging task for the interlocutor, particularly when the communities examined may not be tied to an obvious model of subjectivity. In all social groups people act with, for, and on behalf of other people. Examining whether people act on behalf of others can serve as a means to categorise decision-making as either individual or institutional. The decision to delineate individuals and/or institutions thus becomes a practical emic/etic question that is best answered by the question at hand. The way multiplexity constrains or enables property relations should be the focus of the anthropologist. This means that the method can be used either to examine how people self-conceptualise and describe their relations to an interlocutor or, alternatively, that it can be structured according to empirical observations. The aim should be to identify 
which subset of people and deontic relations provide the greatest explanatory potential, such that generative mechanisms can be identified.

Bhaskar $(1998,13)$ suggested that the retroductive method moves through three steps: 1$)$ Identify a phenomenon; 2) Construct explanations for it, and empirically test these explanations; 3) Identify generative mechanism at work, which subsequently becomes the phenomenon to be explained, and so on. In the context of the approach that was outlined in the previous section, the initial phenomena that are likely to be identified in economic anthropology are exchanges or circulations of objects. Economic interactions are emergent phenomena between two or more people (e.g. exchange, giving, or sharing), and they must therefore be classified through polythetic means; but, because interactions occur at different points in time, the transformation of property rights can be analysed diachronically rather than synchronically. Property rights precede production, consumption and exchange. This means that historical interactions can be examined for the presence of reciprocity and transitivity, allowing economic anthropologists to reveal how close a social structure is to the basic categories that are shown in the following table. In Table 1 we build on the definitions of property described earlier. We therefore provide a preliminary sketch of diachronic transformations of property rights by drawing on the ethnographic record for evidence of ontologically distinct modes of property rights transfer, access and ownership. 


\begin{tabular}{|c|c|c|}
\hline Category & $\begin{array}{c}\text { Graph Example(s) } \\
\text { Nodes }=\text { Agents (individual } \\
\text { or institutional) } \\
\text { Edges }=\text { Transmission of } \\
\text { property rights }\end{array}$ & $\begin{array}{l}\text { Real world examples and } \\
\text { anthropological evidence }\end{array}$ \\
\hline $\begin{array}{l}\text { Intransitive } \\
\text { (closed) }\end{array}$ & & $\begin{array}{l}\text { 'Brute' intransitivity - the good is impossible to exclude from other people, thus } \\
\text { sharing occurs by default e.g. air, sunlight, radiowaves } \\
\text { 'Institutional' intransitivity - property regime prohibits individuals from excluding the } \\
\text { good e.g. common pool resources such as fish stocks and forest timber (Ostrom 1990) }\end{array}$ \\
\hline $\begin{array}{l}\text { Partially } \\
\text { Transitive }\end{array}$ & & $\begin{array}{r}\text { 'Positional' giving - typically between people in different social positions e.g. adult- } \\
\text { child food sharing } \\
\text { (e.g. Elder-Vass 2015) } \\
\text { 'Prosocial exchange systems' (e.g. Harvey 2014) } \\
\text { 'Intracommunity' gift giving - anonymous gifts between strangers at community } \\
\text { celebrations (e.g. Weinberger \& Wallendorf 2011) }\end{array}$ \\
\hline $\begin{array}{l}\text { Indirect } \\
\text { reciprocity }\end{array}$ & & $\begin{array}{l}\text { Intercommunity gift giving }- \text { trade between institutions e.g. Kula ring (Malinowski } \\
\text { 1922/1992) where objects must circulate } \\
\text { Egoist gifts - attempts to demonstrate social status within an institution through giving } \\
\text { or destruction of objects e.g. Moka, Potlatch }\end{array}$ \\
\hline $\begin{array}{c}\text { Direct } \\
\text { reciprocity }\end{array}$ & & $\begin{array}{l}\text { Market exchange - requires commensurable objects and quantitative equivalence } \\
\text { Balanced exchange - ritualised swapping of distinct but qualitatively equivalent } \\
\text { objects }\end{array}$ \\
\hline $\begin{array}{l}\text { Principal(s)- } \\
\quad \text { Agent } \\
\text { relationship } \\
\text { (hierarchical) }\end{array}$ & & $\begin{array}{c}\text { Taxation e.g. Income Tax } \\
\text { Cosmological sacrifice (Hubert\& Mauss 1964) }\end{array}$ \\
\hline $\begin{array}{l}\text { Agent- } \\
\text { Principal(s) } \\
\text { relationship } \\
\text { (hierarchical) }\end{array}$ & & $\begin{array}{l}\text { Redistribution e.g. Welfare } \\
\text { Digital peer-to-peer file sharing (e.g. Giesler 2006) - reciprocity is eschewed in favour } \\
\text { of property regimes that evade reciprocal arrangements for political reasons }\end{array}$ \\
\hline
\end{tabular}

Table 1: Basic categories for diachronic analysis of property rights 
Understanding how multiple spheres of exchange overlap with each other requires a broader understanding of how the objects in question relate to the cosmogony of the people involved, or in other words, how multiplexity influences agency. Empirical tests are unlikely to yield permanently fixed understandings of economic interaction, but this does not mean that they should simply be disregarded. Some of the most urgent political problems involve resource dilemmas that occur across multiplex property relations. In the archetypes of Sahlins and Polanyi that were described earlier the presence of reciprocity plays a central role. However, describing economic relations with so few essentialist categories removes the potential to explain transformation and novelty in social structures. Archetypes should therefore be resisted, unless there is clear empirical evidence for recurring relationships.

We believe that a diachronic form of property right analysis can aid anthropologists in the process of retroductive reasoning. The equality of relationships between people is closely associated with moral questions about economics. For instance, the simplest form of indirect reciprocity that could emerge in an economy, rather than just dyadic reciprocity is shown in table 3 as the first complete triad. By contrast, partially intransitive relationships reveal an imbalance between people, as well as potentially associated moral logics. Imbalance could be due to unconditional gifts or acts of sharing which, as described by Elder-Vass (2015), can only be properly explained if they are understood as positional giving i.e. when the people involved occupy distinct positions within a social structure. The transformative power of agency in these relationships can only be fully explained where structure, agency and culture are all recognised as ontologically distinct. 
With an appropriate dataset, the prevalence of forms can be described statistically, which can then serve as a basis for retroduction. Creating a dataset large enough for diachronic analysis requires that qualitatively distinct property rights are stated and that transformations are recorded through time. Collecting a historical dataset is a difficult task for researchers without the luxury of longitudinal studies, but it may become easier as more of the economy becomes mediated by computers (see for instance, the study of reciprocity on an accommodation sharing website by Lauterbach et al 2009).

\section{Implications and opportunities for future research}

'The study of economic anthropology is ahead of us, not behind, but we must look back if we are to move forward. Economics has the ancient question of value at its core. Economic anthropology has broadened our conception of this problem by drawing attention to the coevality of contradictory value regimes.'

(Gregory 2009,297)

Ethnography and interviews remain the most effective means of understanding the motivations of people within the many forms of political economy, but large-scale longitudinal studies can describe the statistical relations that occur as a consequence of property rights. Descriptive statistics can then be used to help identify the respective generative mechanisms at work and thus inform policy. Ostrom argued that there are no panaceas for developing political economy solutions (e.g. Ostrom et al. 2007). We believe mixed-method approaches are most likely to both reveal cultural tensions resulting from property rights and help shed light on potential solutions.

There are many areas where a critical realist informed economic anthropology can provide insight. Resource dilemmas, for instance, are rife throughout international 
politics at inter-governmental and intra-governmental levels. Understanding how accessbased property rights can work in the absence of alienable property rights is therefore arguably one of the most urgent political issues of the moment. This has two clear corollaries: 1) The way the 'economy' itself is measured; and 2) How politics can promote harmonious arrangements within and between different social groups. The emphasis on exchange within developed economies has led to the widespread assumption that quantitative growth in the possession and exchange of alienable property rights is the only morally legitimate political end (Appel, 2017). GDP and measures that privilege exchange have therefore come to be a largely unquestioned means through which moral progress is measured (Coyle, 2014). To challenge this dogma means redefining the terms of the debate, so that growth in exchange is no longer seen as a prerequisite for a functioning economy. The variety of existing economies demands that researchers find terms of comparison sufficiently nuanced to accommodate the mixture of metaphysical beliefs that people hold. We have argued that only diachronic analysis of multiplex property rights can properly illustrate the basis of economic cooperation, and that such forms of investigation are only possible with ethnographers and statisticians working in tandem. This also necessitates a grounding in ontological realism and epistemic relativism that the critical realist literature is best placed to provide. Economic anthropology has had a lasting influence on researchers, but it has struggled to maintain itself as a discipline in the 20th Century, primarily because of a failure of engagement between formalists and substantivists. Researchers from both heritages contributed enormously to our understanding of economic life around the world, but it is imperative that the ontological debate does not run out of steam. Critical realism may offer the most promising way to stoke the fire. 


\section{References}

Appadurai, A. 1988. Introduction: commodities and the politics of value. In The social life of things (ed.) A. Appadurai. New York: Cambridge University Press.

Appel, H. 2017 Toward an Ethnography of the National Economy, Cultural Anthropology 32, no.2: 294-322

Archer M.S. 1982. Morphogenesis versus structuration: on combining structure and action. British Journal Sociology 33(4):455-483

Archer M.S. 1995. Realist social theory: the morphogenetic approach. Cambridge University Press, Cambridge

Archer, M.S. 2000. Being Human: The Problem of Agency, Cambridge University Press: Cambridge

Archer M.S. 2007. Making our way through the world: human reflexivity and social mobility. Cambridge University Press, Cambridge

Archer, M.S. 2012. The reflexive imperative in late Modernity. Cambridge University Press: Cambridge

Ashraf, J. and Uddin, S. 2015. Management Accounting Research and Structuration Theory: A Critical Realist Critique, Journal of Critical Realism, Vol. 14, Issue 5, 485507 
Becker, G. S. 1976. The Economic Approach to Human Behavior, Chicago, University of Chicago Press

Belk RW. 2010. Sharing. Journal of Consumer Research, 365:715-734

Bhaskar, R. 1975/1977. A realist theory of science, London: Verso

Bhaskar, R. 1998. The Possibility of Naturalism: A philosophical critique of the contemporary human sciences, Third edition. London: Routledge

Bhaskar, R. 2002/2012. From Science to Emancipation: Alienation and the Actuality of Enlightenment. London: Sage.

Bonnington, O. 2015. The Indispensability of Reflexivity to Practice: The Case of Home Energy Efficiency, Journal of Critical Realism, Vol. 14, Issue 5,461-484

Bourdieu, P. 1977. Outline of a theory of practice. Cambridge: Cambridge University Press

Bourdieu, P. 1984. Distinction: A social critique of the judgement of taste, Oxon: Routledge

Bryant, L. 2011. The Democracy of Objects, Ann Arbor: Open Humanities Press 
Busse, M. W. 2013. Property. In Carrier, J. (Ed.) A Handbook of Economic Anthropology. Cheltenham, UK: Edward Elgar.

Caillé, A. 2014. Anti-utilitarianism, economics, and the gift-paradigm. Revue du Mauss [Online] Available at : http://www.revuedumauss.com.fr/media/ACstake.pdf, Date accessed: 20/04/2016

Carrier J.G. 2005. A Handbook of Economic Anthropology. Northampton, MA: Edward Elgar

Chibnik, M. 2015. Virtual Issue - Economic Anthropology: Introduction, American Anthropologist [Online] Available at: http://anthrosource.onlinelibrary.wiley.com/hub/journal/10.1111/(ISSN)15481433/economic-anthropology.html, Date Accessed: 01/06/2016

Cook, S. 1966. The Obsolete 'Anti-Market' Mentality: A Critique of the Substantive Approach to Economic Anthropology, American Anthropologist, New Series, Vol. 68, No. 2, Part 1, 323-345

Coyle, D. 2014. GDP: A Brief but Affectionate History. Princeton, N.J.: Princeton University Press.

Crawford, S.E.S. and Ostrom, E. 1995. The grammar of institutions. American political science review. Vol. 89, No. 3 
da Col, Giovanni 2015. Incomplete regularities. Comparison, values, personhood, Hau: Journal of Ethnographic Theory, 5, 1: i-vii.

Dalton, G. 1961. Economic Theory and Primitive Society, American Anthropologist $63(1): 1-25$

DeLanda, M. 2006. A new philosophy of society: assemblage theory and social complexity. London: Continuum.

DeLanda, M. 2016. Assemblage Theory, Edinburgh University Press

Descola, P. 2013. Beyond nature and culture. Translated by Janet Lloyd. Chicago: University of Chicago Press

Descola, P. 2014. Modes of being and forms of predication, Colloquium, Hau: Journal of Ethnographic Theory 4 (1): 271-280.

Donati, P. and Archer, M. S. 2015. The Relational Subject, Cambridge: Cambridge University Press

Elder-Vass, D. 2015. Free gifts and positional gifts: Beyond exchangeism, European Journal of Social Theory, 18 (4), 451-468. 
Endicott, K. 1988. Property, Power and Conflict among the Batek of Malaysia, in Ingold, T., Riches, D., and Woodburn, J. (eds.) Hunters and Gatherers, New York: St. Martin's Press, pp. 110- 127

Evans-Pritchard, E.E. 1940. The Nuer. A Description of the Modes of Livelihood and Political Institutions of a Nilotic People. Oxford University Press, Oxford

Everett, D. 2005. Cultural constraints on grammar and cognition in Pirahã: Another look at the design features of human language, Current Anthropology, Volume 46, Number 4

Everett, D. 2009. Pirahã culture and grammar: A response to some criticisms. Language 85.405-42.

Fiske,A. P. 1991. Structures of Social Life: The Four Elementary Forms of Human Relations. New York: The Free Press.

Fiske, A. P. 1992. The four elementary forms of sociality: Framework for a unified theory of social relations, Psychological Review, Vol. 99, No. 4, 689-723

Gibson, T. 1985. The sharing of substance versus the sharing of activity among the Buid, Man, 20:391-411

Giesler M. 2006. Consumer gift systems. Journal of Consumer Research 33(2): 283290. 
Godelier, M. 2004/2011. The Metamorphoses of Kinship, Verso: London

Gorski, P. S. 2013. What is critical realism? And why should you care? Contemporary Sociology: A Journal of Reviews, 42, 658

Graeber, D. 2001. Toward an anthropological theory of value: The false coin of our own dreams. New York: Palgrave

Graeber, D. 2015. Radical alterity is just another way of saying "reality" A reply to Eduardo Viveiros de Castro, Hau: Journal of Ethnographic Theory 5 (2): 1-41

Granovetter, M. 1985. "Economic action and social structure: the problem of embeddedness". The American Journal of Sociology 91 (3): 487

Gregory C 2009. Whatever happened to economic anthropology? The Australian Journal of Anthropology 20: 285-300

Gudeman, S. 2008. Economy's tension: the dialectics of community and markets. Oxford: Berghahn Books

Hage, P. and Harary, F. 1996. Island Networks: Communication, Kinship, and Classification Structure in Oceania. New York: Cambridge University Press.

Hartwig, M. (2007, xvii) Introduction, in A Realist Theory of Science by Bhaskar, R. London: Routledge 
Hann, C., and Hart, K. 2011. Economic anthropology. Cambridge, UK: Polity Press.

Harman, G. 2010. Towards Speculative Realism: Essays and Lectures, Zero Books:

Winchester

Harman, G. 2016. Immaterialism: Objects and Social Theory, Polity Press

Harvey, J, Smith, A. and Golightly, D. 2014. Giving and sharing in the computermediated economy, Journal of Consumer Behaviour, 14, 5: 1479-1487

Hess, C. and Ostrom, E. 2003. Ideas, Artifacts, and Facilities: Information as a CommonPool Resource, Law and Contemporary Problems 66, S. 111-146

Hofer, J. 1982. The History of the Hutterites. Winnipeg: W. K. Printers' Aid

Hubert, H. and Mauss, M. 1964. Sacrifice: Its nature and function. London: Cohen \& West

Janzen, R., and Stanton, M 2010. The Hutterites in North America. Baltimore: Johns Hopkins University Press.

Latour, B. 2005. Reassembling the social: an introduction to actor network-theory.

Oxford: Oxford University Press. 
Laughlin, C. 1993. Fuzziness and phenomenology in ethnological research: Insights from fuzzy-set theory. Journal of Anthropological Research, 49, 17-37.

Lauterbach, D., Truong, H., Shah, T., and Adamic, L. 2009. Surfing a web of trust: Reputation and reciprocity on couchsurfing. In Proceedings of the 2009 International Conference on Computational Science and Engineering, volume 4, 346-353

Lawson, T. 2003. Reorienting Economics, London and New York: Routledge

Levi-Strauss, C. 1949/1969. The elementary structure of kinship. London: Eyre and Spottiswoode

Levi-Strauss, C. 1955/2011. Tristes Tropiques, trans. Weightman, J. and Weightman, D., London: Penguin Books

Longhofer, J. 1993. All Things in Common: The Contingent Nature of Communalism Among the Hutterites.” Journal of Mennonite Studies 11:174-193.

Malafouris L. 2013. How things shape the mind: a theory of material engagement. Cambridge: MIT Press

Malinowski, B. 1922/1992. Argonauts of the Western Pacific, London: Routledge and Kegan Paul.

Mauss, M. 1950/2002. The Gift, Oxon: Routledge Classics 
Mosko, M. 2010. Partible penitents: dividual personhood and Christian practice in Melanesia and the West, Journal of the Royal Anthropological Institute (N.S.) 16, 215240

Musgrave, R. A. 1959. The theory of public finance, New York: McGraw-Hill

Needham, R. 1975. Polythetic Classification: Convergence and Consequences. Man $10: 349-369$

Nevins, A, Pesetsky, D. and Rodrigues, C. 2009. Pirahã exceptionality: A reassessment. Language 85.355-404.

Ostrom, E. 1990. Governing the Commons: The Evolution of Institutions for Collective Action. Cambridge: Cambridge University Press.

Ostrom, E. 2003. How types of goods and property rights jointly affect collective action. Journal of Theoretical Politics, 15(3), 239-270.

Ostrom, E. 2005. Understanding Institutional Diversity. Princeton, NJ: Princeton University Press

Ostrom, E. and Hess, C. 2007. A framework for analyzing the knowledge commons, in Understanding Knowledge as a Commons: From Theory to Practice, Edited by Hess, C. and Ostrom, E. 
Ostrom, E., Janssen, M.A., and Anderies, J.M., 2007. Going beyond panaceas.

Proceedings of the National Academy of Sciences of the U.S.A. 104 (39): 15176-15178.

Ostrom, E. and Schlager, E. 1996. The formation of property rights, in Susan Hanna, Carl Fole, and Karl-Goran Maler (eds) Rights to Nature pp. 127-56. Washington, D.C>: Island Press

Polanyi, K. 1944. The Great Transformation. Boston: Beacon Press

Polanyi, K. 1957. The economy as instituted process. In Polanyi, K., Arensberg, C. and Pearson, H. (eds.), Trade and market in the early empires: Economies in history and Theory. Glencoe, Ill.: The Free Press

Peter, K., and Whitaker, I. 1981. The Acquisition of Personal Property among Hutterites and Its Social Dimensions, Anthropologica, 23(2), 145-155.

Porpora, D. 2015. Reconstructing sociology: The critical realist approach. New York, NY: Cambridge University Press.

Radcliffe-Brown, A. 1965., Structure and Function in Primitive Society. New York: The Free Press 
Sahlins, M. 1968. On the Sociology of primitive exchange, in The Relevance of Models for Social Anthropology. London: Tavistock Publications

Sahlins, M. 1969. Economic anthropology and anthropological economics. Social Sci. Info. 8, 13-33.

Sahlins, M. 1979. Stone Age Economics, Chicago: Aldine-Atherton.

Samuelson, P. 1954. The pure theory of public expenditure, Review of economics and expenditure, 36 (Nov), 387-9

Simmel, G. 1950. The sociology of Georg Simmel, edited by K. Wolff. New York: Free Press

Sinha, C., Sinha, V.D.S., Zinken, J., and Sampaio, W. 2011. When time is not space: The social and linguistic construction of time intervals and temporal event relations in an Amazonian culture. Language and Cognition, 3, 137-169.

Smart, A. 1993. Gifts, bribes, and guanxi: A reconsideration of Bourdieu's social capital. Cultural Anthropology, 8: 388-408

Strathern, M. 1988. The gender of the gift: problems with women and problems with society in Melanesia. Berkeley: University of California Press. 
Verdery, K. and Humphrey, C. 2004. Property in Question: Value Transformation in the Global Economy. Oxford and New York: Berg Press.

Viveiros de Castro, E. 2015. Who is Afraid of the Ontological Wolf?: Some Comments on an Ongoing Anthropological Debate. The Cambridge Journal of Anthropology 33(1):2-16.

Wagner, R. 1991. 'The fractal person', in M. Godelier and M. Strathern (eds) Big Men and Great Men: Personifications of Power in Melanesia, Cambridge: Cambridge University Press

Weinberger M.F. and Wallendorf, M. 2011. Intracommunity gifting at the intersection of contemporary moral and market economies. Journal of Consumer Research 39: 7492.

Wilk, R. and Cliggett, L. 2007., Economies and Cultures: Foundations of Economic Anthropology, 2nd ed., Cambridge, MA: Westview.

Wittgenstein, L. 1961. Tractatus logico-philosophicus, London: Routledge

\footnotetext{
${ }^{\mathrm{i}}$ Analytical hybridity has also influenced consumer behaviour researchers interested in distinguishing between giving, sharing and exchange (e.g. Belk 2010; Harvey et al 2014).
} 